\title{
Caries prevalence and treatment needs of healthy and medically compromised children at a tertiary care institution in Saudi Arabia
}

A. Brown ${ }^{1}$

$$
\text { ألتشار التسوُّس ومتطلبات المعالجة في الأطفال الأصحاء وغير الأصحاء في مؤسسة للرعاية التخصصية في }
$$

الخلاصـة: تقدّم هذه الدر اسة معلو مات عن معدَّل انتشار التسوُّس ومتطلبات المعالجة لدى المرضى الأطفال من غير

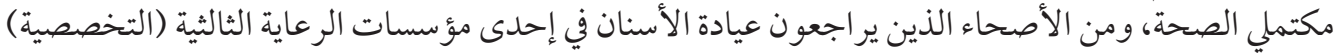

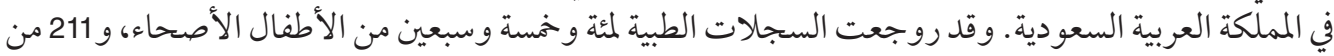

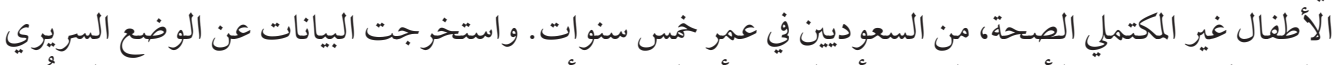

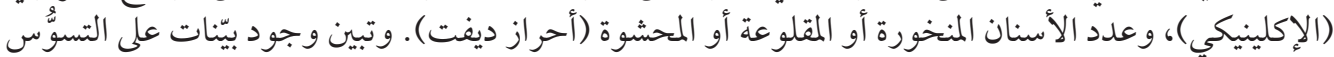

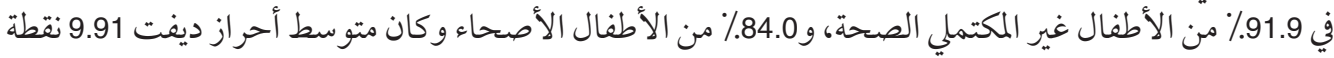

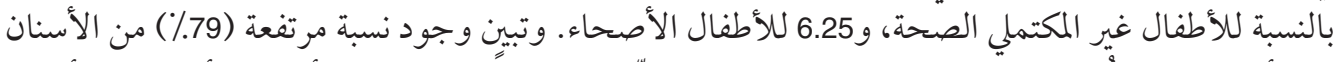

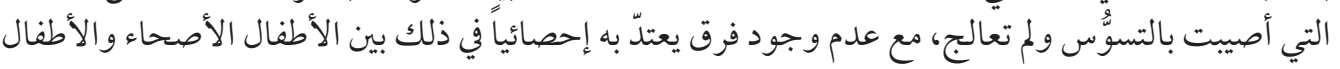
غير المكتملي الصحة.

ABSTRACT We examined the caries prevalence and treatment needs of medically compromised and healthy paediatric patients attending the dental clinic of a tertiary care institution in Saudi Arabia. The medical records of 175 healthy and 211 medically compromised 5-year-old Saudi children were reviewed. Data was extracted on clinical status and number of decayed, extracted and filled teeth (deft score). A total of $91.9 \%$ of medically compromised and $84.0 \%$ of healthy children had evidence of caries. Mean deft score was 9.91 for medically compromised and 6.25 for healthy children. A high proportion of carious teeth $(79 \%)$ were untreated, with no significant difference between the 2 groups.

Prévalence des caries chez les enfants en bonne et en mauvaise santé fréquentant un établissement de soins tertiaires en Arabie saoudite, et besoins en traitement de ces enfants RÉSUMÉ Nous avons examiné la prévalence des caries chez les patients pédiatriques en bonne et en mauvaise santé qui fréquentaient le service clinique dentaire d'un établissement de soins tertiaires en Arabie saoudite, ainsi que sur les besoins en traitement de ces patients. Le dossier médical d'enfants saoudiens âgés de 5 ans, dont 175 en bonne santé et 211 ayant des problèmes de santé, a été examiné. On a relevé les données relatives à leur état clinique ainsi qu'à leur indice CAO (nombre de dents cariées, absentes (extraites) et obturées). Au total, $91.9 \%$ des enfants ayant des problèmes de santé et $84.0 \%$ des enfants en bonne santé présentaient des signes de carie. L'indice CAO moyen était de 9,91 chez les enfants en mauvaise santé et de 6,25 chez les enfants en bonne santé. Le pourcentage de dents cariées non traitées était très élevé $(79 \%)$, sans qu'il existe de différence significative entre les deux catégories d'enfants.

${ }^{1}$ King Faisal Specialist Hospital and Research Centre, Riyadh, Saudi Arabia (Correspondence to: alisonbrown40@hotmail.com).

Received: 11/06/06; accepted: 05/09/06

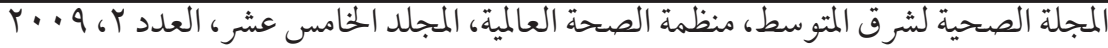




\section{Introduction}

While oral problems may have a considerable impact on the general health status and quality of life of otherwise healthy children, their effect on those with chronic and acute illnesses can be much more serious. In particular, children with cardiac disease or history of cardiac surgery, disorders of haemostasis, anaemia, malignant disease, respiratory disorders, myelosuppression, immunodeficiencies, renal and liver diseases, endocrine and metabolic disorders, and some musculoskeletal disorders are at increased risk of sometimes life-threatening complications. The quality of life of children with mental, developmental or physical disabilities may be further compromised by dental pain and infection. Treatment options and outcomes for children with cleft lip and palate, and craniofacial and dental anomalies can also be adversely affected by dental caries [1].

In a recent article, Petersen et al. emphasized that, although there have been great improvements in the oral health status of populations in many countries, at the global level it is still poor [2]. In general, the incidence of dental caries in children is increasing in developing countries but decreasing in developed countries. However, it remains high in the latter among those who are socially, economically and medically disadvantaged.

Saudi Arabia has been described as a middle-income developing country. A total of $43 \%$ of the citizens are under 14 years of age [3]. The first oral health survey, which was undertaken in 1987, found that 6-yearold males had a mean total of 4.1 decayed, extracted and/or filled primary teeth (deft) and females had 3.5 [4]. In 1996, 5 years later, the deft score for 6-year-olds had increased to 5.54 [5], and in 1998 to 6.4 [6]. By 2002, it had reached 7.3 [7] and the latest paper, published in 2006, reported a mean deft of 8.06 [8].

In 1981 the World Health Organization (WHO) and World Dental Federation set a goal that by the year $200050 \%$ of 5-6-yearolds should be caries-free [9]. Two recent screening exercises in Jeddah, Saudi Arabia reported evidence of dental caries in $83 \%$ and $96 \%$ of children $[8,10]$.

Dental caries is the leading reason for Saudi children to need extraction of primary teeth [11], but most decayed teeth remain untreated [12]. With a population growth rate of over $3 \%$ per year [3], and hence an ever increasing number of children, the social and economic burden associated with the rising incidence of dental disease in childhood requires serious consideration.

Caries risk assessment tools and guidelines classify children with special health care needs as high risk [13]. This includes medically compromised children as well as those with physical, mental, sensory, behavioural, cognitive and emotional impairments. Published results of studies on caries prevalence in these children are often contradictory. For example, most investigators have reported higher caries rates for children with congenital heart disease [14], whereas others have found rates similar to those of matched healthy controls [15]. The consensus is that few medical conditions are associated with an increased caries risk per se, but because oral hygiene is generally worse in medically compromised children, and their exposure to additional risk factors greater, they are more prone to developing carious lesions. These risk factors may include frequent intake of cariogenic foods and drinks, regular use of sugar-sweetened medicines [16] and poor salivary flow and buffering capacity [17].

Furthermore, most studies also found that medically compromised children were less likely to be receiving regular dental

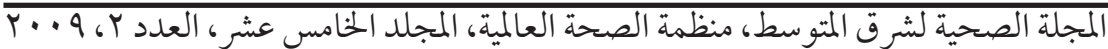


care than their healthy counterparts. Fewer were taken to the dentist for asymptomatic check-ups and preventive interventions [18], and more missed scheduled appointments [19]. When they did present for treatment, they were more liable to have carious teeth extracted than restored [20]. A study in the United Kingdom found that many general dental practitioners did not feel confident providing treatment for medically compromised children [21]. In a large number of countries in the Eastern Mediterranean Region, including Saudi Arabia, access to specialist paediatric dentists is limited.

There is almost no information available on the caries status of Saudi children with special health care needs. An increased prevalence of caries has been reported in boys with wasting and stunting [22], and in girls who were blind, deaf and mentally retarded [23]. The aim of this study, therefore, was to compare the caries prevalence and treatment needs of healthy and medically compromised 5-year-old children attending a dental clinic in Riyadh, Saudi Arabia.

\section{Methods}

This study was conducted in the dental clinic of a tertiary care hospital in Riyadh, Saudi Arabia. The clinic provides specialist care for several thousand children per year, $50 \%$ of whom are medically compromised. The medical records of all 5-year-old Saudi children treated at the dental clinic between 1 January 2001 and 31 December 2002 were extracted from the department database. Each child's medical chart was reviewed to establish his/her dental and medical status at the first appointment in the study period. Children had been examined by 1 of 4 paediatric dentists and posterior bitewing radiographs were taken whenever possible.
Caries status was evaluated using the decayed, extracted and filled primary teeth (deft) index [24]. The deft score for each subject was the sum of the number of primary teeth decayed $(\mathrm{dt})$, extracted as a result of caries (et) and filled (ft). Teeth were recorded as decayed when a carious lesion was detectable either clinically or radiographically, whether cavitated or not. They were also recorded as decayed if they had temporary restorations or sealants and/ or permanent restorations in association with carious lesions. Filled teeth were defined as those with one or more permanent restorations and no evidence of decay.

Caries prevalence was defined as the percentage of the study population affected with dental caries ( $\%$ deft). Treatment need was estimated by calculating the percentage of decayed teeth that were untreated $(\% \mathrm{dt} /$ deft).

The child's medical condition was classified as one of the following: healthy; cardiac disease; haematology or oncology disorder; immunodeficiency; cleft lip/palate or craniofacial disorder; metabolic or neurodegenerative disease; endocrine disorder; renal disease; or other mental or physical disorder. Patients seen for emergency care only or with a genetic syndrome known to cause absence or early loss of primary teeth were excluded from the study.

The independent samples $t$-test was used to check the significance of the difference in mean deft scores of healthy and medically compromised children, as well as healthy and disease-specific clinical subgroups with 20 or more subjects. Significance of differences in caries prevalence and percentage of untreated decayed teeth were tested using the chi-squared test. Because of the multiplicity of statistical tests being performed, the level of statistical significance was adjusted using Bonferroni's correction [25]. 
Dividing the type 1 error rate by the number of tests gave a significance level of 0.005 .

The study was approved by the institutional Clinical Research and Research Ethics Committees, who waived the need for informed consent.

\section{Results}

The study population consisted of 386 children of whom 175 were healthy and 211 medically compromised. The characteristics of the children in terms of clinical group and sex are shown in Table 1. Only 4 clinical subgroups contained 20 or more subjects: haematology/oncology, cardiac, cleft lip/palate/craniofacial, and metabolic/ neurodegenerative.

Caries prevalence was high; $88.3 \%$ of the children had 1 or more teeth decayed, extracted or restored. More of the medically compromised $(91.9 \%)$ than the healthy children $(84.0 \%)$ had carious teeth, but not significantly so. In the clinical subgroups with 20 or more subjects, the haematology/ oncology group had the fewest children caries-free (Table 2).
Mean deft score was 8.25 overall. There was a significant difference between the medically compromised (9.91) and healthy (6.25) children for mean deft scores $(P$ $<0.001)$. Those with cardiac disease had the highest mean deft (11.95), followed by the cleft lip/palate/craniofacial (10.06), metabolic/neurodegenerative (9.95) and haematology/oncology (9.66) subgroups $(P$ $<0.001$ ) (Table 3).

A large percentage of carious teeth were untreated $(79.4 \%)$, with no difference between healthy and medically compromised children overall. However, there was a significant difference at the 0.001 level with 2 of the clinical subgroups. The haematology/oncology patients had a greater and the cleft lip/palate/craniofacial patients a lesser degree of unmet treatment need than the healthy children (Table 4).

\section{Discussion}

The caries status of the medically compromised children seen in the dental clinic was considerably worse than that of the healthy children. However, although significant

\begin{tabular}{|c|c|c|c|c|c|}
\hline \multirow[t]{2}{*}{ Variable } & \multicolumn{2}{|c|}{ Males } & \multicolumn{2}{|c|}{ Females } & \multirow{2}{*}{$\begin{array}{c}\text { Total } \\
\text { No. }\end{array}$} \\
\hline & No. & $\%$ & No. & $\%$ & \\
\hline \multicolumn{6}{|l|}{ Clinical group } \\
\hline Healthy & 87 & 49.7 & 88 & 50.3 & 175 \\
\hline Medically compromised & 116 & 55.0 & 95 & 45.0 & 211 \\
\hline \multicolumn{6}{|l|}{ Clinical subgroup } \\
\hline Haematology/oncology disorder & 23 & 56.1 & 18 & 43.9 & 41 \\
\hline Cardiac disease & 22 & 56.4 & 17 & 43.6 & 39 \\
\hline Cleft lip/palate/craniofacial disorder & 20 & 62.5 & 12 & 37.5 & 32 \\
\hline Metabolic/neurodegenerative disorder & 11 & 52.4 & 10 & 47.6 & 21 \\
\hline Skeletal disorder & 6 & 66.7 & 3 & 33.3 & 9 \\
\hline Endocrine disorder & 6 & 66.7 & 3 & 33.3 & 9 \\
\hline Immunodeficiency & 4 & 57.1 & 3 & 42.9 & 7 \\
\hline Renal disease & 2 & 33.3 & 4 & 66.7 & 6 \\
\hline Other mental and/or physical disorder & 22 & 46.8 & 25 & 53.2 & 47 \\
\hline
\end{tabular}

المجلة الصحية لشرق المتوسط، منظمة الصحة العالمية، المجلد الخامس عشر، العدد ب، 9.بr 


\begin{tabular}{|c|c|c|c|}
\hline \multicolumn{4}{|c|}{$\begin{array}{l}\text { Table } 2 \text { Number and percentage of study children affected with dental } \\
\text { caries (\% deft) by clinical status and significance of difference with } \\
\text { healthy children }\end{array}$} \\
\hline Variable & $\begin{array}{l}\text { No. of children } \\
\text { with deft }\end{array}$ & $\%$ deft & $P$-value ${ }^{a}$ \\
\hline \multicolumn{4}{|l|}{ Clinical group } \\
\hline All & 341 & 88.3 & \\
\hline Healthy & 147 & 84.0 & \\
\hline Medically compromised & 194 & 91.9 & 0.024 \\
\hline \multicolumn{4}{|l|}{ Clinical subgroup } \\
\hline Haematology/oncology & 40 & 97.6 & 0.041 \\
\hline Cardiac & 38 & 97.4 & 0.05 \\
\hline Cleft lip/palate/craniofacial & 29 & 90.6 & 0.48 \\
\hline Metabolic/neurodegenerative & 20 & 95.2 & 0.296 \\
\hline
\end{tabular}

differences in mean deft scores were demonstrated between the 2 groups, they were not for caries prevalence. In other words, although the extent of caries was lower in the healthy group, few were caries-free. While this was not a population-based study, it is very likely this pattern reflects that of the community at large. First, the prevalence of dental caries and mean deft score of the healthy children were similar to those reported recently by other investigators in Saudi Arabia. Secondly, many overseas studies also found that medically compromised children had a higher mean deft than healthy children.

It was not possible to pinpoint one risk factor, or a set of risk factors, responsible for the disparity between healthy and medically compromised children's caries status in the study population. Exposure to oral health education and preventive interventions, as well as children's manual dexterity, extent of parental assistance with toothbrushing and dietary habits differed

\begin{tabular}{|c|c|c|c|}
\hline Variable & Mean deft score & SD & $P$-value ${ }^{a}$ \\
\hline \multicolumn{4}{|l|}{ Clinical group } \\
\hline All & 8.25 & 5.52 & - \\
\hline Healthy & 6.25 & 4.71 & - \\
\hline Medically compromised & 9.91 & 5.61 & $<0.001$ \\
\hline \multicolumn{4}{|l|}{ Clinical subgroup } \\
\hline Haematology/oncology & 9.66 & 5.71 & $<0.001$ \\
\hline Cardiac & 11.95 & 4.51 & $<0.001$ \\
\hline Cleft lip/palate/craniofacial & 10.06 & 5.86 & 0.001 \\
\hline Metabolic/neurodegenerative & 9.95 & 5.42 & 0.001 \\
\hline
\end{tabular}




\begin{tabular}{|c|c|c|c|c|}
\hline Variable & $\begin{array}{c}\text { dt } \\
\text { No. of teeth }\end{array}$ & $\begin{array}{c}\text { deft } \\
\text { No. of teeth }\end{array}$ & $\begin{array}{c}\text { dt } / \text { deft } \\
\%\end{array}$ & $P$-value ${ }^{a}$ \\
\hline \multicolumn{5}{|l|}{ Clinical group } \\
\hline All & 2529 & 3184 & 79.4 & - \\
\hline Healthy & 868 & 1094 & 79.3 & - \\
\hline Medically compromised & 1661 & 2090 & 79.5 & 0.93 \\
\hline \multicolumn{5}{|l|}{ Clinical subgroup } \\
\hline Haematology/oncology & 373 & 396 & 94.2 & $<0.001$ \\
\hline Cardiac & 354 & 466 & 76.0 & 0.141 \\
\hline Cleft lip/palate/craniofacial & 201 & 322 & 62.4 & $<0.001$ \\
\hline Metabolic/neurodegenerative & 174 & 209 & 83.3 & 0.195 \\
\hline
\end{tabular}

substantially between individuals in each group. Oral hygiene was generally poor. But, unfortunately, the association between plaque level, clinical group and caries rate could not be tested because the children's oral hygiene had been recorded in a narrative fashion rather than given a score.

Many of the medically compromised children were taking sugar-sweetened liquid oral medicines on a regular basis. Some, in particular the haematology/oncology patients, were suffering from hyposalivation caused by their drugs, medical treatment or disease process itself. But no risk factor was universally present in any clinical subgroup. The inconsistent results obtained by comparable studies elsewhere probably stem from a similar multiplicity in type and extent of caries risk factors between individual children.

At present most Saudi mothers have a low level of dental knowledge and their children have poor oral hygiene habits, as well as repeated exposure to sugary food and drinks [26]. Breast- and bottle-feeding are often continued for several years and have been associated with high level of early childhood caries [27]. Widespread public health education is required to ad- dress this problem. In 1996 the Jeddah Primary Health Care Directorate launched an annual health campaign in primary schools which included diet and oral hygiene education activities [10]. This could serve as a good model for other regions.

One further area of concern identified was the high percentage of dental decay that had not been treated. This was true for all the children, both healthy and medically compromised. In most other countries chronically sick children have a considerably greater unmet treatment need than healthy children, but there was no difference in this study population. A small number of the healthy children had attended the dental clinic regularly but the majority only presented after problems had developed. On the whole, few Saudis go to the dentist in the absence of pain [28] and untreated dental decay is widespread in the general community. As with diet and oral hygiene habits, a public health approach is needed to encourage regular dental visits.

However, it is especially important that medically compromised children, who are more susceptible to systemic complications secondary to oral infections, receive additional advice on dental health, and specialist

المجلة الصحية لشرق المتوسط، منظمة الصحة العالمية، المجلد الخامس عشر، العدد Y، 9 +. 
dental care when required. Virtually all the children in the cleft lip/palate/craniofacial subgroup had been followed by a paediatric dentist from a very early age and this was reflected in their significantly lower percentage of untreated decayed teeth than the healthy children. Their regular dental visits included dietary and oral hygiene advice, as well as topical fluoride applications. Unfortunately, this did not appear to have led to a similar reduction in caries rate. Effective tooth cleaning is particularly challenging in children with clefts due to their misaligned teeth and the results of this study suggest they need more frequent reinforcement of good oral health habits.

Most other medically compromised children were only referred to the dental clinic by their primary care physician either because they already had caries and needed dental treatment, or required "clearance" prior to cardiac surgery or organ or bone marrow transplant. Since this study was completed, a thrice-weekly satellite dental clinic has been started at the children's cancer hospital associated with this institution. The mission is to provide a more proactive approach to the oral care of children with malignant disease. The paediatric oncologists are referring newly-diagnosed patients for preventive education and care and treatment of active dental disease prior to commencement of chemotherapy, radiation therapy and bone marrow transplant. Furthermore, children are followed in the clinic on a regular basis during, and for several years after, completion of cancer therapy. This initiative should go some way towards reducing the unmet treatment need, and acute and long-term oral complications that may develop in paediatric haematology/oncology patients. Ongoing monitoring will provide data with which to evaluate the effectiveness of the programme and make improvements, as needed, in the future.
A limitation of this research project was the lack of information available on the children's oral hygiene status and socioeconomic background. It would be helpful for analytical purposes if these could be recorded in the medical charts using a scoring system.

The next step is to expand the provision of preventive dental services for other medically compromised children treated at this hospital by increasing the number of clinic sessions reserved solely for these patients. Through raising awareness among physicians of the need for early referral, and improving access to dental care, the aim will be to fully integrate oral health promotion with the overall disease management.

In the World Health Report 2003 Petersen re-emphasized the need for action to improve the oral health of all the population while reducing inequities through strategies that target groups at highest risk [29]. Governments and communities have a fundamental role to play in achieving these objectives, but health care professionals have a particular responsibility towards those with special health care needs. Employing the hospital's existing outreach resources, the knowledge and experience gained by the professionals at this institution should be shared with those working in regional health care settings so that similar programmes may be developed countrywide.

In conclusion, this study has provided baseline information on the disparity between the caries status and treatment needs of healthy and medically compromised 5 yearold Saudi children at a single institution. The results will be useful for comparison with future research both in this country and the Eastern Mediterranean Region. They also highlight the need for improvement in public health education and services provided for the prevention, early detection and treatment of dental caries for all Saudi children. 


\section{References}

1. American Academy of Pediatric Dentistry. Clinical guideline on management of persons with special health care needs. Pediatric dentistry, 2004, 26(7):77-80.

2. Petersen PE et al. The global burden of oral diseases and risks to oral health. Bulletin of the World Health Organization, 2005, 83(9):661-9.

3. Central Department of Statistics. Kingdom of Saudi Arabia [website] (http:// www.cdsi.gov.sa/showproductstandard. aspx?lid=26\&pid=1420, accessed 21 May 2008).

4. Al-Shammari A et al. An oral health survey of Saudi Arabia: phase 1 (Riyadh). Riyadh, Saudi Arabia, King Saud University Press, 1991.

5. Alamoudi N, Salako NO, Massoud I. Caries experience in children aged 6-9 years in Jeddah, Saudi Arabia. International journal of paediatric dentistry, 1996, 6(2):101-5.

6. Al-Tamimi S, Peterson PE. Oral health situation of schoolchildren, mothers and schoolteachers in Saudi Arabia. International dental journal, 1998, 48(3):180-6.

7. Al-Wazzan KA. Dental caries prevalence in 6-7-year-old schoolchildren in Riyadh region: a comparative study with the 1987 Oral Health Survey of Saudi Arabia Phase 1. Saudi dental journal, 2004, 16:54-60.

8. Al-Malik MI, Rehbini YA. Prevalence of dental caries, severity and pattern in age 6 to 7 -year-old children in a selected community in Saudi Arabia. Journal of contemporary dental practice, 2006, 7(2):46-54.

9. Fédération Dentaire Internationale/World Health Organization. Global goals for oral health in the year 2000. International dental journal, 1982, 23:74-7.
10. Gandeh MBS, Milaat WA. Dental caries among schoolchildren: report of a health education campaign in Jeddah, Saudi Arabia. Eastern Mediterranean health journal, 2000, 6(2-3):396-401.

11. Farsi JMA. Common causes of extraction of teeth in Saudi Arabia. Saudi dental journal, 1992, 4(3):101-5.

12. Wyne AH et al. Caries prevalence, severity and pattern in pre-school children. Saudi medical journal, 2002, 23(5):580-4.

13. American Academy of Pediatric Dentistry. Caries-risk assessment tool. Pediatric dentistry, 2004, 26(7):198.

14. Stecksen-Blicks C et al. Dental caries experience in children with congenital heart disease: a case control study. International journal of paediatric dentistry, 2004, 14(2):94-100.

15. Franco E et al. Dental disease, caries related microflora and salivary $\lg A$ of children with severe congenital cardiac disease: and epidemiological and oral microbial survey. Pediatric dentistry, 1996, 18(3):228-35.

16. Saghal J, Sood PB, Raju OS. A comparison of oral hygiene status and dental caries in children on long term liquid oral medications to those not administered with such medications. Journal of the Indian Society of Pedodontics and Preventive Dentistry, 2002, 20(4):144-51.

17. Leone CW, Oppenheim FG. Physical and chemical aspects of saliva as indicators of risk for dental caries in humans. Journal of dental education, 2001, 65(10):1054-62.

18. Desai M, Messer LB, Calache H. A study of the dental treatment needs of children with disabilities in Melbourne, Australia. Australian dental journal, 2001, 46(1):4150. 
19. Clark EL, Stern MR, Rodd HD. Investigation of missed appointments amongst cleft lip and palate children. International journal of paediatric dentistry, 2005, 15:391.

20. Bradley C, McAlister T. The oral health of children with Down syndrome in Ireland. Special care dentistry, 2004, 24(2):5560.

21. Parry JA, Khan FA. Provision of dental care for medically compromised children in the UK by general dental practitioners. International journal of paediatric dentistry, 2000, 10(4):322-77.

22. Abolfotouh MA et al. Dental caries: experience in relation to wasting and stunted growth among schoolboys in Abha, Saudi Arabia. Annals of Saudi medicine, 2000, 20(5-6):360-3.

23. Al-Qhatani Z, Wyne AH. Caries experience and oral hygiene status of blind, deaf and mentally retarded female children in Riyadh, Saudi Arabia. Odontostomatology tropicale, 2004, 27(105):37-40.

24. Oral health surveys, basic methods, 3rd ed. Geneva, World Health Organization, 1987.
25. Bonferroni CE. II calcolo delle assicurazioni su gruppi di teste. In: Studie in onore del Professore Salvatore Ortu Carboni. Rome, Italy, 1935:13-60.

26. Al-Tamimi S, Peterson PE. Oral health situation of schoolchildren, mothers and schoolteachers in Saudi Arabia. International dental journal, 1998, 48(3):180-6.

27. Wyne AH, Chohan AN, Al-Begomi R. Feeding and dietary practices of nursing caries children in Riyadh, Saudi Arabia. Odontostomatology tropicale, 2002, 25(100):37-42.

28. Farsi JM, Farghaly MM, Farsi N. Oral health knowledge, attitude and behaviour among Saudi school students in Jeddah city. Journal of dentistry, 2004, 32(1):4753.

29. Petersen PE. The world oral health report 2003. Continuous improvement of oral health in the 21st century: the approach of the WHO Global Oral Health Programme. Geneva, World Health Organization, 2003. 